\title{
KORELASI MULTIVARIATE EL NIÑO SOUTHERN OSCILLATOR INDEX DAN VARIASI PERMUKAAN LAUT DI PERAIRAN INDONESIA
}

\author{
Eko Yuli Handoko*1, Yuwono ${ }^{2}$, Reni Ariani ${ }^{3}$, Ragfinsa Budiaski Filaili ${ }^{4}$ \\ ${ }^{123}$ Departemen Teknik Geomatika; Kampus ITS Sukolilo, Surabaya, 60111, Indonesia \\ *e-mail: ekoyh@geodesy.its.ac.id
}

\begin{abstract}
Abstrak
Lautan Indonesia merupakan wilayah perairan yang merupakan penghubung antara Lautan Pasifik dan Lautan Hindia, serta Laut China Selatan. Variasi permukaan laut yang relatif tinggi di bagian barat Lautan Pasifik mempengaruhi variasi laut di perairan Indonesia. Salah satu penyebab variasi permukaan laut di kawasan ini adalah pengaruh fenomena $E I$ Niño Southern Oscillation. Penelitian ini bertujuan melakukan perhitungan korelasi antara El Niño Southern Oscillation dan variasi permukaan laut di perairan Indonesia. Hitungan korelasi menggunakan Multivariate El Niño Southern Oscillation memberikan hasil adanya korelasi kuat negatif antara El Niño Southern Oscillation dan variasi permukaan laut sebesar $-0,8$.
\end{abstract}

Kata kunci : Satelit altimetri, Multivariate El Nino Southern Oscillation, variasi permukaan laut, perairan Indonesia

\section{PENDAHULUAN}

Permukaan laut rata-rata secara global merepresentasikan ketinggian rata-rata dari permukaan laut relatif terhadap pusat bumi. Peningkatan permukaan laut rata-rata dapat dilihat secata fisik sebagai perubahan volume lautan dan bentuk basin laut. Perubahan volume laut disebabkan oleh perubahan temperatur dan masuknya air segar yang berasal dari daratan terkait mencairnya es kutub dan glasial.

Pemantauan kenaikan permukaan laut secara global menggunakan data pengukuran satelit altimetri mencapai 3,4 $\mathrm{mm}$ per tahun (Ablain dkk, 2016). Berdasarkan pengamatan satelit altimetri mengindikasikan bahwa kecepatan kenaikan permukaan laut tidak merata / tidak sama di setiap lautan (Nicholls dan Cazenave, 2010). Beberapa wilayah, kenaikan permukaan laut lebih cepat dibandingan wilayah lainnya, contohnya laju kenaikan permukaan laut lebih cepat di wilayah barat lautan Pasifik di banding di wilayah timur. Tingginya variasi permukaan laut di wilayah Lautan Pasifik didominasi oleh fenomena EI Niño Southern Oscillation (ENSO) yang terdiri dari EI Niño dan La Niña Indonesia terletak di antara Lautan Pasifik dan Lautan Hindia (Cazenave dkk, 2012; Church, White dan Hunter, 2006).

Lautan Indonesia yang terletak diantara Lautan Pasifik dan Lautan Hindia, merupakan jalur pertukaran arus dari kedua lautan tersebut, atau yang disebut Indonesian Throughflow (ITF). Suhu dan salinitas menjadi faktor penting dalam variasi permukaan laut, sehingga dalam hal ini ITF menegang peranan penting dalam sirkulasi laut global dan regional.

Beberapa penelitian, Lautan Indonesia dipengaruhi oleh lautan sekitarnya, seperti Lautan Pasifik (Chang dkk., 2013; van Sebille dkk, 2014), Lautan Hindia (Saji dan Yamagata, 2003; Lan, Wong dan Han, 2008) dan Lautan Laut China Selatan (Gordon dkk, 2012).

ENSO adalah fenomena yang terjadi akibat adanya penyimpangan kondisi interaksi antara lautan dan atmosfer di sepanjang Samudera Pasifik sekitar ekuator dari keadaan normalnya sehingga mempengaruhi variabilitas iklim di wilayah ekuator samudera Pasifik dan beberapa bagian bumi. El Niño terjadi ketika suhu permukaan laut di bagian timur Samudera Pasifik meningkat, namun suhu di barat Samudera Pasifik dan sekitar Indonesia mengalami penurunan (penyimpangan) sehingga curah hujan menurun. Hal sebaliknya akan terjadi ketika fenomena La Niña. Untuk mengetahui fenomena ENSO (dapat dilihat dari indikator anomali suhu permukaan laut, Indeks Osilasi Selatan (SOI), dan elevasi permukaan laut (Rejeki dkk. 2017).

Posisi Indonesia yang berada di Inter-Tropical Convergence Zone (ITCZ) menyebabkan cuaca dan iklim di Indonesia dipengaruhi fenomena ENSO. 
Pengaruh ENSO berbeda-beda antar wilayah bergantung pada lokasi dan topografi (Qian, Robertson, dan Moron 2010). ENSO akan mempengaruhi keadaan meteo-oseanografi yaitu kondisi curah hujan di darat maupun laut, suhu permukaan laut, dan tinggi permukaan laut.

Dengan karakteristik Lautan Indonesia yang dipengaruhi Lautan sekitar dan fenomena ENSO, Penelitian ini berfokus untuk mengetahui seberapa besar pengaruh ENSO terhadap lautan Indonesia dengan menghitung korelasi antara ENSO indeks dan detrended Sea Level Anomaly.

\section{DATA DAN METODE}

Multivariate ENSO Index (MEI) adalah indeks yang paling mewakili fenomena ENSO. Multivariate ENSO Index (MEI) adalah ukuran multivarian dari sinyal ENSO yang didasarkan dari 6 variabel meteorologi utama pada ekuator Pasifik yaitu tekanan permukaan laut (P), komponen zonal (U) dan meridional angin permukaan $(V)$, suhu permukaan laut (S), suhu permukaan udara (A), dan total cloudiness fraction of the sky (C). Pengamatan ini telah dikumpulkan dan diterbitkan dalam Comperehensive OceanAtmosphere Data Set (COADS) selama bertahuntahun. COADS adalah database digital berisi data cuaca dari pengamatan kapal dan buoy cuaca. Data MEI diambil dari Laut wilayah Pasifik tropis dengan batas $30^{\circ} \mathrm{LU}-30^{\circ} \mathrm{LS}$ dan $100^{\circ} \mathrm{BT}-70^{\circ} \mathrm{BB}$. Nilai negatif/rendah dari MEl mewakili tahap ENSO yang dingin ( $L a$ Nina), sedangkan nilai positif /tinggi MEI mewakili hangat fase ENSO (EI Nino). Nilai setiap bulan dipusatkan antara bulan sebelum dan berikutnya, misalkan nilai Januari mewakili nilai yang berpusat antara DesemberJanuari dan seterusnya. Nilai MEI distandarisasi dengan referensi periode 1950 -1993 dan dihitung sebagai first unrotated principal component (PC) dari kombinasi keenam variabel yang diamati (Mazzarella, Giuliacci, dan Liritzis 2010).

Dalam penelitian ini, indeks ENSO yang digunakan adalah (MEI). Data MEI tersedia dalam website NOAA (www.esrl.noaa.gov/psd/enso/mei/) dan dapat diundung secara gratis. Periode data yang digunakan antara 1993 hingga 2017.

Data variasi permukaan laut di Lautan Indonesia menggunakan data pengamatan Altimetri satelit TOPEX/Poseidon, Jason-1, Jason-2 dan Jason-3.
Data pengamatan tersebut meliputi lautan Indonesia dengan batas $20^{\circ}$ Lintang Selatan hingga $13^{\circ}$ Lintang Utara dan $90^{\circ}$ hingga $144^{\circ}$ Bujur Timur dalam periode dari tahun 1993 hingga 2017.

Data satelit altimetri yang digunakan merupakan ekstraksi dari Radar Altimeter Database System (RADS). RADS dikembangkan Delft Institute for Eatrh-Oriented Space Research (DEOS) yang bekerja sama dengan NOAA's Laboratory for Satellite altimetry (Scharroo, 2012).

Dalam pengolahan data altimetri, terdapat beberapa hal yang dilakukan antara lain:

- Pengolahan data untuk mengestimasi Sea Level Anomaly (SLA) untuk masing-masing satelit menggunakan persamaan 1. Besaran-besaran parameter yang digunakan dalam menentukan SLA berdasarkan penelitian Handoko, Fernandes dan Lazaro (2017).

- Dalam menjaga kekontinyuan SLA dari berbagai data altimetri, perlu dilakukan inter-calibrated, yaitu memberikan koreksi kepada misi-misi satelit terhadap misi referensi. Dalam hal ini, satelit TOPEX/Posidon dijadikan sebagai satelit referensi, sedangkan satelit lainnya, seperti Jason-1, Jason-2 dan Jason-3 harus diberikan koreksi mengacu kepada satelit referensi.

- Data SLA yang telah dikalibrasi kemudian dilakukan detrending agar dapat dibandingkan dengan indeks ENSO.

- Nilai indeks ENSO, dalam hal ini menggunakan $\mathrm{MEI}$ disusun dan dihitung nilai korelasinya dengan detrended SLA.

Penjabaran dari hal tersebut di atas akan dijelaskan lebih detail di bawah ini.

Prinsip satelit altimetri dapat dijelaskan sebagai berikut: altimeter mengirimkan pulsa pendek radiasi microwave dengan kekuatan yang diketahui terhadap permukaan laut. Pulsa berinteraksi dengan permukaan laut sesaat dan sebagian radiasi altimeter akan terefleksi kembali ke altimeter. Teknik penentuan jarak dengan radar yaitu dari waktu untuk perjalanan pulsa pulang-pergi antara satelit dan permukaan laut. Jarak dari satelit ke mean sea level adalah estimasi dari perjalanan pulang-pergi (Chelton dkk. 2001). Namun untuk mendapatkan data altimetri yang memberikan hasil baik, beberapa koreksi harus diberikan. Koreksi 
tersebut antara lain: koreksi kering dan basah dari troposfer (dry and wet tropospheric corrections), koreksi ionosfer, koreksi sea state bias, koreksi pasang surut, dynamic atmospheric correction.

Dalam studi variasi permukaan laut, Sea Level Anomaly (SLA) digunakan sebagai acuan untuk

$$
h_{S L A}=H-R_{O b s}-\Delta h_{d r y}-\Delta h_{w e t}-\Delta h_{\text {iono }}-\Delta h_{S S B}-h_{D A C}-h_{\text {tides }}-h_{m s s}
$$

Dimana $R_{\text {obs }}$ adalah jarak antara satelit dan permukaan laut setelah dikoreksi kesalahan instrument, $\Delta h_{\text {dry }}$ dan $\Delta h_{\text {wet }}$ merupakan koreksi komponen kering dan basah troposfer, $\Delta h_{\text {iono }}$ adalah koreksi ionosfer, $\Delta h_{S S B}$ adalah koreksi sea state bias, $h_{D A C}$ adalah dynamic atmospheric correction, $h_{\text {tides }}$ merupakan gabungan koreksi ocean tide, load tide solid earth tide dan pole tide, sedangkan $h_{m s s}$ adalah mean sea surface model.

$$
S L A_{\text {Corrected }}(\mathrm{J} 1)=S L A(\mathrm{~J} 1)-\operatorname{bias}(\mathrm{J} 1, \mathrm{TP})
$$

$$
S L A_{\text {Corrected }}(\mathrm{J} 2)=S L A(\mathrm{~J} 2)-\operatorname{bias}(\mathrm{J} 2, \mathrm{~J} 1)-\operatorname{bias}(\mathrm{J} 1, \mathrm{TP})
$$

$$
S L A_{\text {Corrected }}(\mathrm{J} 3)=S L A(\mathrm{~J} 2)-\operatorname{bias}(\mathrm{J} 3, \mathrm{~J} 2)-\operatorname{bias}(\mathrm{J} 2, \mathrm{~J} 1)-\operatorname{bias}(\mathrm{J} 1, \mathrm{TP})
$$

Dekomposisi time series merupakan hal penting dalam banyak konteks dimana variasi musiman dalam data time series diamati. Detrending adalah proses menghilangakan tren linier dari suatu time series, biasanya

digunakan untuk proses Fast Fourier Transform (FFT). Tren linier adalah kecenderungan data dimana perubahannya berdasarkan waktu adalah tetap. Detrending digunakan untuk menghilangkan distorsi pada proses korelasi dan untuk mendapatkan data yang stasioner. Umumnya, time series dapat dianggap sebagai kombinasi banyak komponen dengan frekuensi yang berbeda. Transformasi Fourier dapat menguraikan seri yang diberikan ke dalam komponen ini, dan komponen terdekomposisi dapat direkonstruksi kembali ke seri asli menggunakan inverse Fourier transform.
Persamaan untuk mendapatkan detren terdapat pada persamaan berikut:

Detrend data $=$ Raw data - trend data $(5)$

Korelasi merupakan istilah yang digunakan untuk mengukur kekuatan hubungan antar variabel. Analisis korelasi adalah cara untuk mengetahui ada atau tidak adanya hubungan antarvariabel misalnya hubungan dua variabel. Dalam penelitian ini, korelasi dilakukan antara MEI dan detrended SLA.

\section{HASIL DAN PEMBAHASAN}

Dalam menentikan SLA masing masing satelit, menggunakan parameter dari Handoko, Fernandes, dan Lazaro (2017), seperti dalam tabel 1. 
Tabel 1. Pareeter Model Koreksi yang Digunakan

\begin{tabular}{lcccc}
\hline Parameter & T / P & Jason-1 & Jason-2 & Jason-3 \\
\hline DTC & ERA- & ERA- & ERA- & ERA- \\
& Interim & Interim & Interim & Interim \\
& DTC & DTC & DTC & DTC \\
\hline WTC & ERA- & ERA- & ERA- & ERA- \\
& Interim & Interim & Interim & Interim \\
& WTC & WTC & WTC & WTC \\
\hline Ionosfer & smoothed & smoothed & smoothed & smoothed \\
& dual & dual & dual & dual \\
& frequency & frequency & frequency & frequency \\
\hline SSB & CLS non- & Tran2012 & Tran2012 & Tran2012 \\
& parametric & non- & non- & non- \\
& & parametric & parametric & parametric \\
\hline DAC & local & local & local & local \\
& mean of & mean of & mean of & mean of \\
& MOG2D & MOG2D & MOG2D & MOG2D \\
\hline Tides & GOT4.10 & GOT4.10 & GOT4.10 & GOT4.10 \\
\hline MSS & CNES- & CNES- & CNES- & CNES- \\
& CLS11 & CLS15 & CLS15 & CLS15 \\
\hline
\end{tabular}

Nilai SLA dirata-rata setiap cycle dibobotkan berdasarkan lintang dengan cosinus lintang. Kemudian proses gridding dilakukan dengan tujuan untuk mengisi kekosongan data terhadap nilai lintang-bujur, agar didapatkan hasil pemodelan yang lebih baik. Gridding SLA dilakukan dengan ukuran $3^{\circ} \times 3^{\circ}$, sebelumnya harus dihitung terlebih dahulu untuk setiap period (10 hari) untuk mendistribusikan pengukuran yang sama di seluruh permukaan lautan.

Proses inter-calibrated missions, antara satelit Topex/Poseidon dengan Jason terdapat tandem misi 21 cycle yaitu cycle 1-21 Jason 1 dan cycle 344 - 364 T/P. Untuk tandem misi satelit Jason 1 dengan Jason 2 adalah cycle $240-260$ pada Jason 1 dan Jason 2 adalah cycle $1-21$. Tandem misi satelit Jason 2 dan jason 3 adalah cycle 1-23 pada Jason 3 dan cycle 281-303 pada Jason 2. Nilai bias antara satelit Jason-1 dengan T/P adalah $0,619 \mathrm{~mm}$, nilai bias antara Jason 1 dan Jason 2 adalah $-18,16 \mathrm{~mm}$, dan nilai bias anatara Jason-2 dengan Jason-3 adalah 50,09 mm. Setelah mendapatkan bias kemudian nilai mean SLA Jason 1 , 2, dan 3 dikoreksi dengan persamaan (2) - (5).

Selanjutnya, dengan diperolehnya nilai bias dari masing-masing satelit relatif terhadap satelit referensi, maka ditentukan nilai rata-rata SLA time series untuk lautan Indonesia.

Menggunakan metode detrending SLA time series, hitungan korelasi antara indek $\mathrm{MEI}$ dan variasi permukaan laut dapat ditentukan.Nilai korelasi ditentukan tiap grid engan ukuran $3^{\circ} \times 3^{\circ}$. Hasil dapat dilihat pada gambar 1.

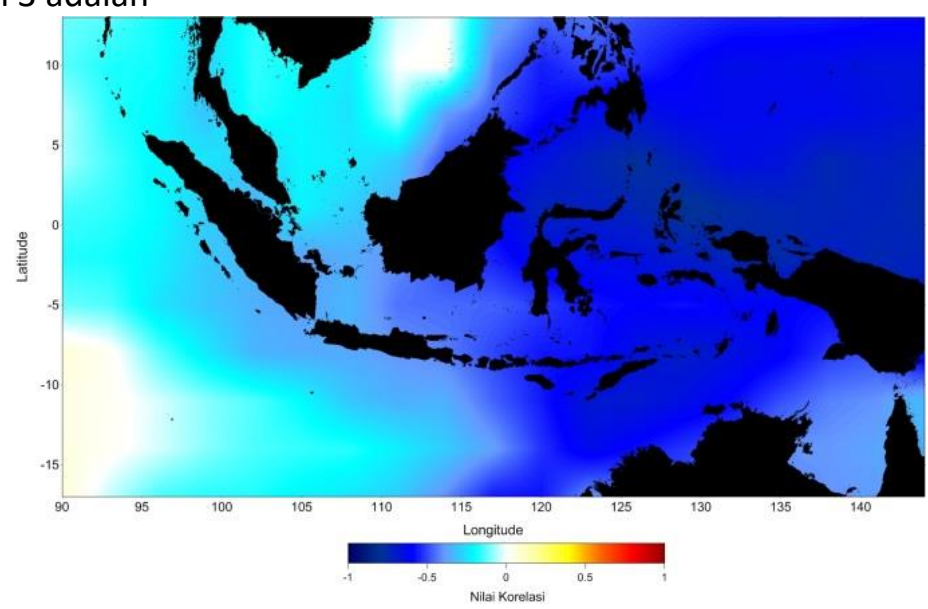

Gambar 1. Nilai Korelasi Antara MEI dan Detrended SLA 


\section{KESIMPULAN}

Hitungan korelasi antara indeks ENSO dan variasi permukaan laut di perairan Indonesia dalam periode 1993 - 2017 telah dilakukan. Dalam penelitian ini, korelasi antara MEI dan detrend SLA mempunyai nilai korelasi tinggi sebesar $-0,8$, tanda negatif mempunya arti korelasi berkebalikan. Secara pola spasial, nilai korelasi tinggi terdapat di perairan yang dekat dengan wilayah bagian barat lautan Pasifik. Semakin jauh dari wilayah Lautan Pasifik memperlihatkan korelasi yang kecil, sehingga dapat diartikan pengaruhnya semakin kecil

\section{DAFTAR PUSTAKA}

Ablain, M., Legeais, J. F., Prandi, P., Marcos, M., FenoglioMarc, L., Dieng, H. B., . . Cazenave, A. (2016). Satellite Altimetry-Based Sea Level at Global and Regional Scales. Surveys in Geophysics, 38(1), 731. doi:10.1007/s10712-016-9389-8

Cazenave, A., Henry, O., Munier, S., Delcroix, T., Gordon, A. L., Meyssignac, B., . . Becker, M. (2012). Estimating ENSO Influence on the Global Mean Sea Level, 1993-2010. Marine Geodesy, 35(sup1), 82-97. doi:10.1080/01490419.2012.718209

Chang, Y.-T., Du, L., Zhang, S.-W., \& Huang, P.-F. (2013). Sea level variations in the tropical Pacific Ocean during two types of recent El Niño events. Global and Planetary Change, 108, 119-127. doi:10.1016/j.gloplacha.2013.06.001

Chelton, D. B., Ries, J. C., Haines, B. J., Fu, L. L., \& Callahan, P. S. (2001). Satellite Altimetry. In L. L. Fu \& A. Cazenave (Eds.), Satellite Altimetry and Earth Sciences: A Handbook of Techniques and Applications (pp. 1-132). San Diego: Academic Press.

Church, J. A., White, N. J., \& Hunter, J. R. (2006). Sea-level rise at tropical Pacific and Indian Ocean islands. Global and Planetary Change, 53(3), 155-168. doi:10.1016/j.gloplacha.2006.04.001

Gordon, A. L., Huber, B. A., Metzger, E. J., Susanto, R. D., Hurlburt, H. E., \& Adi, T. R. (2012). South China Sea throughflow impact on the Indonesian throughflow. Geophysical Research Letters, 39(11). doi:10.1029/2012gl052021

Handoko, E., Fernandes, M., \& Lázaro, C. (2017). Assessment of Altimetric Range and Geophysical Corrections and Mean Sea Surface ModelsImpacts on Sea Level Variability around the Indonesian Seas. Remote Sensing, 9(2), 102. doi:10.3390/rs9020102

Lan, J., Hong, J., \& Wang, Y. (2008). Relationship of the interannual variability of the Indonesian
Throughflow with the IOD over the tropical Indian Ocean. Theoretical and Applied Climatology, 97(1-2), 75-79. doi:10.1007/s00704-008-0066-9

Masters, D., Nerem, R. S., Choe, C., Leuliette, E., Beckley, B., White, N., \& Ablain, M. (2012). Comparison of Global Mean Sea Level Time Series from TOPEX/Poseidon, Jason-1, and Jason-2. Marine Geodesy, 35(sup1), 20-41. doi:10.1080/01490419.2012.717862

Mazzarella, A., Giuliacci, A., \& Liritzis, I. (2010). On the 60month cycle of multivariate ENSO index. Springer, 23-27. https://doi.org/10.1007/s00704-009-0159-0

Nicholls, R. J., \& Cazenave, A. (2010). Sea-level rise and its impact on coastal zones. Science, 328(5985), 1517-1520. doi:10.1126/science.1185782

Qian, J. H., Robertson, A. W., \& Moron, V. (2010). Interaction Among ENSO, the Monsoon, and Diurnal Cycle in Rainfall Variability Over JAva, Indonesia. Journal of the Atmospheric Sciences, (67), 3509-3524

Rejeki, H. A., Munasik, \& Kunarso. (2017). The Effect of ENSO to the Variability of Sea Surface Height in Western Pacific Ocean and Eastern Indian Ocean and its Connectivity to the Indonesia Throughflow (ITF). IOP Conference Series: Earth and Enviromental Science 55. https://doi.org/10.1088/17426596/755/1/011001

Scharroo, R. (2012). RADS version 3.1 - User Manual and Format Specification.

Van Sebille, E., Sprintall, J., Schwarzkopf, F. U., Gupta, A. S., Santoso, A., England, M. H., . . Boning, C. W. (2014). Pacific-to-Indian Ocean connectivity: Tasman leakage, Indonesian Throughflow, and the role of ENSO. J. Geophys. Res. Oceans, 119, 1365-1382. doi:10.1002/2013JC009525 